\title{
Use of bicycle ergometry and sustained handgrip exercise in the diagnosis of presence and extent of coronary heart disease
}

\author{
Richard H. Helfant, Vidya S. Banka, Maria A. DeVilla, Rogelio Pine, Venkat Kabde, and \\ Steven G. Meister \\ From the University of Pennsylvania School of Medicine, Presbyterian-University of Pennsylvania Medical \\ Center, Philadelphia, Penn., U.S.A.
}

The present study examines the efficacy of the exercise electrocardiogram using the isotonic bicycle ergometer and isometric handgrip in predicting the extent of coronary obstructive disease, coronary collaterals, and abnormalities of left ventricular contraction (asynergy) in 65 patients. Of 32 patients with a normal isotonic exercise electrocardiogram, 25 had a normal coronary arteriogram $(78 \cdot 1 \%)$. Of the $32,7(21 \cdot 9 \%)$ were false negatives (normal exercise electrocardiogram with abnormal coronary arteriogram). Conversely, 5 of $3 I$ patients $(16 \cdot I \%)$ were false positives (abnormal exercise electrocardiogram with normal coronary arteriogram). In contrast, only 3 of 53 patients tested with isometric handgrip had abnormal electrocardiograms. This correlated with the finding that the product of systolic pressure and heart rate achieved with bicycle ergometry was significantly higher $(P<0.01)$ than that with isometric handgrip.

In the patients with abnormal coronary arteriograms, a correlation was found between the magnitude of ischaemic ST depression and the extent of coronary obstructive disease. Thus, 9 of the I4 patients with o and $I \cdot 0 \mathrm{~mm} S T$ segment depression exhibited one-vessel coronary disease, while only $I$ of the I9 patients with $2 \cdot 0$ or greater than $2.0 \mathrm{~mm} S T$ segment depression had one vessel disease $(P<0.005)$. A correlation was also found between the degree of ST segment depression and the presence of coronary collaterals. Only 3 of 14 patients with 0 and $0 \cdot 1 \mathrm{~mm} S T$ segment depression exhibited collaterals, while I4 of 19 patients with $2 \cdot 0$ or greater than $2.0 \mathrm{~mm} S T$ segment depression exhibited collateral vessels $(P<0.005)$. A similar correlation was also found between the degree of ST segment depression and the presence of asynergy. The results indicate that bicycle ergometry exercise to 70 per cent of maximum predicted heart rate is of considerable value in the diagnosis of both the presence and extent of coronary artery disease. In contrast, isometric handgrip exercise is of no value in this regard.

Although the exercise electrocardiogram has been used clinically for over 30 years (Master and Jaffe, I94I), its specificity and sensitivity in diagnosing the presence of coronary heart disease has remained controversial. Several groups of investigators have attempted to correlate the Master Two Step Test and the coronary arteriogram with variable results (Elliott and Gorlin, 1966; Mason et al., 1967; Demany, Tambe, and Zimmerman, 1967; Most, Kemp, and Gorlin, 1969). More recently the use of 'graded exercise tests' to maximal or submaximal levels of predicted heart rate have been advocated as more 'physiological' methods of exercise testing (Bruce and Hornsten, 1969). Though the use of

Received 30 July 1973. submaximal exercise testing using a bicycle ergometer or treadmill has yielded an increased number of patients with abnormal ST segment depression (Sheffield, Holt, and Reeves, 1965), to date there have been few studies comparing the results of this form of exercise testing with coronary arteriography (Roitman, Jones, and Sheffield, I970). In addition, no systematic study has been made correlating the degree of ST segment abnormality produced by submaximal exercise stress with the extent of coronary obstructive disease delineated angiographically. Similarly, the relation of the coronary collateral circulation and localized ventricular contraction abnormalities (asynergy) to the results of submaximal exercise stress testing requires further examination. 
The present study compares the results of submaximal exercise stress testing (to $70 \%$ of maximum predicted heart rate) with the presence and severity of coronary obstructive disease (determined by selective coronary arteriography), coronary collaterals, and asynergy. In addition, the use of isometric handgrip exercise in unmasking electrocardiographic evidence of ischaemia was also examined. This stress test has been found useful in uncovering abnormalities of ventricular performance in patients with coronary heart disease.

\section{Subjects and methods}

Sixty-five patients referred for the evaluation of chest discomfort were selected for study on the following basis: (I) the chest discomfort was of a relatively stable nature (without significant change over the past three months); (2) no evidence of valvular or congenital heart disease existed (by catheterization); (3) no cardioactive medications were being taken within the week before exercise testing (i.e. digitalis, diuretics, antiarrhythmics, propranolol, or long-acting nitrates); (4) standard resting electrocardiogram was within normal limits or there was only minimal and nonspecific ST or T wave abnormalities and the monitor exercise lead (modified V5) was within normal limits at rest.

On the day before cardiac catheterization, and at least 2 hours after eating lunch, the patient was brought to the exercise laboratory where a resting electrocardiogram was taken. At this time a bicycle ergometer (Monark) exercise test was performed with a 300 kilopond (kpm) metre $/ \mathrm{min}$ initially and an increase of $300 \mathrm{kpm} / \mathrm{min}$ every 3 minutes until: ( $I$ ) anginal chest discomfort was produced; (2) significant ( $2 \mathrm{~mm}$ ) ST segment depression was observed on the monitor lead; (3) two or more ventricular premature complexes per minute appeared; (4) a minimum of 70 per cent of the maximum predicted heart rate was achieved. Heart rate and blood pressure, taken by means of a sphygmomanometer, were recorded at rest and at $\mathrm{I}$-minute intervals during the exercise test.

After a 15- to 30-minute rest period, and when the monitor trace had returned to the baseline, sustained isometric handgrip exercise was performed using the method previously described (Helfant, DeVilla, and Meister, 1971a). Electrocardiogram, blood pressure, and pulse response were monitored, as with bicycle ergometry.

Criteria for an abnormal exercise test were defined as the development of $\mathrm{I} .0 \mathrm{~mm}$ or more 'ischaemic' (horizontal or down sloping) ST depression lasting $0.08 \mathrm{sec}$ or longer and occurring either during or after exercise. The baseline was taken as the line connecting two consecutive PR intervals. Electrocardiographic data were interpreted by two independent observers without knowledge of the patient's history and before cardiac catheterization and coronary arteriography.

On the morning after the stress testing, the patient was taken to the cardiac catheterization laboratory in the postabsorptive state. Right heart catheterization was performed via an antecubital vein cut down, and left heart catheterization was performed either via a right brachial arteriotomy or percutaneously using the right or left femoral artery. After haemodynamic measurements had been determined, a left ventricular cineangiogram was obtained in the right anterior oblique projection and selective cine-coronary arteriography was carried out using either the Sones or Judkins technique. Cine films were taken on a to by 6 in. dual field image amplifier (Siemens) at 64 frames per second using $35 \mathrm{~mm}$ Kodak Shellburst film.

Significant obstructive coronary disease was defined as greater than 75 per cent stenosis of the left main, left anterior descending, circumflex, and/or right coronary arteries. The left ventriculogram was analysed for uniformity and vigour of contraction, and localized abnormalities of ventricular contraction (asynergy) were defined as hypokinetic (diminished contraction), akinetic (no contraction), or dyskinetic (paradoxical systolic expansion).

\section{Results}

Correlation of bicycle ergometry exercise and coronary arteriography

The results of bicycle ergometry exercise testing in comparison to the coronary arteriographic findings are depicted in Table $\mathrm{I}$. Of 32 patients with a normal exercise electrocardiogram, 25 had a normal coronary arteriogram $(78 \cdot 1 \%)$. Of the 32,7 , or 22

TABLE I Correlation of bicycle ergometry exercise and coronary arteriography

\begin{tabular}{|c|c|c|c|}
\hline Exercise & No. of & Coronary a & riograms \\
\hline electrocardiogram & patients & Normal & Abnormal \\
\hline $\begin{array}{l}\text { Normal } \\
\text { Abnormal }\end{array}$ & $\begin{array}{l}32 \\
31\end{array}$ & $\begin{array}{r}25(78 \cdot 1 \%) \\
5(16 \cdot 1 \%)\end{array}$ & $\begin{array}{r}7(21 \cdot 9 \%) \\
26(83.9 \%)\end{array}$ \\
\hline
\end{tabular}

per cent, were false negatives in that a normal exercise electrocardiogram was found with abnormal coronary arteriograms (Table 1 ). Conversely, 5 of 31 patients $(16 \cdot 1 \%)$ had an abnormal exercise electrocardiogram with a normal coronary arteriogram (false positives). Of the 5, 2 were women diagnosed as having the syndrome of true angina pectoris with normal coronary arteriograms and 2 others had voltage criteria for left ventricular hypertrophy.

Two patients, both with abnormal arteriograms, developed bundle-branch block with exercise and are excluded from further analysis.

\section{Correlation of isometric handgrip exercise and coronary arteriography}

In contrast to bicycle ergometry testing, only 3 of 53 patients tested with isometric handgrip exercise had abnormal electrocardiogram results (Table 2). These 
TABLE 2 Correlation of isometric handgrip exercise and coronary arteriography

\begin{tabular}{|c|c|c|c|}
\hline $\begin{array}{l}\text { Exercise } \\
\text { electrocardiogram }\end{array}$ & $\begin{array}{l}\text { No. of } \\
\text { patients }\end{array}$ & $\begin{array}{l}\text { Coronary } \\
\text { Normal }\end{array}$ & $\begin{array}{l}\text { eriograms } \\
\text { Abnormal }\end{array}$ \\
\hline Normal & 50 & 22 & 28 \\
\hline Abnormal & 3 & 0 & 3 \\
\hline
\end{tabular}

3 patients had abnormal coronary arteriograms. All 3 had I mm ST segment depression, and in all of these bicycle ergometry exercise resulted in $2 \mathrm{~mm}$ or greater ST segment depression. Of 50 patients with no handgrip electrocardiographic abnormalities, 28 (or $56 \%$ ) had abnormal coronary arteriograms.

When the systolic pressure-heart rate product achieved with isometric handgrip is contrasted with that of bicycle ergometry exercise, the results are seen in Fig. 1 . The increase in the double product with handgrip is not statistically significant, while bicycle ergometry exercise produced a significantly higher rate-pressure product $(P<0.01)$ than that produced with handgrip (Fig. I).

\section{Correlation of degree of ST segment depres- sion with extent of coronary artery disease}

In the 33 patients with abnormal arteriograms, a correlation was found between the magnitude of ischaemic ST depression and the extent of coronary obstructive disease. Table 3 illustrates that as the amount of ST segment depression increases, a corresponding increase is also seen in the number of diseased coronary vessels. Of the 14 patients with 0 and I mm ST segment depression, 9 had I vessel disease, 3 had 2 vessel disease, and 2 had 3 vessel disease (Fig. 2). In contrast, of those with 2 or greater than $2 \mathrm{~mm}$ ST segment depression, only I of I9 had I vessel disease $(P<0.005)$. The remaining 18 patients were equally divided between those with 2 and 3 vessel disease (Fig. 2).

TABLE 3 Correlation of degree of ST segment depression with extent of coronary artery disease

\begin{tabular}{lllll}
\hline \multirow{S}{S}{$\begin{array}{l}\text { No. of } \\
\text { depression (mm) }\end{array}$} & \multicolumn{3}{c}{ No. of vessels involved } \\
patients & I & 2 & 3 \\
\hline 0 & 7 & 4 & 2 & $\mathrm{I}$ \\
$\mathrm{I}$ & 7 & 5 & 1 & $\mathrm{I}$ \\
2 & 9 & 0 & 4 & 5 \\
$>2$ & 10 & $\mathrm{I}$ & 5 & 4 \\
\hline
\end{tabular}

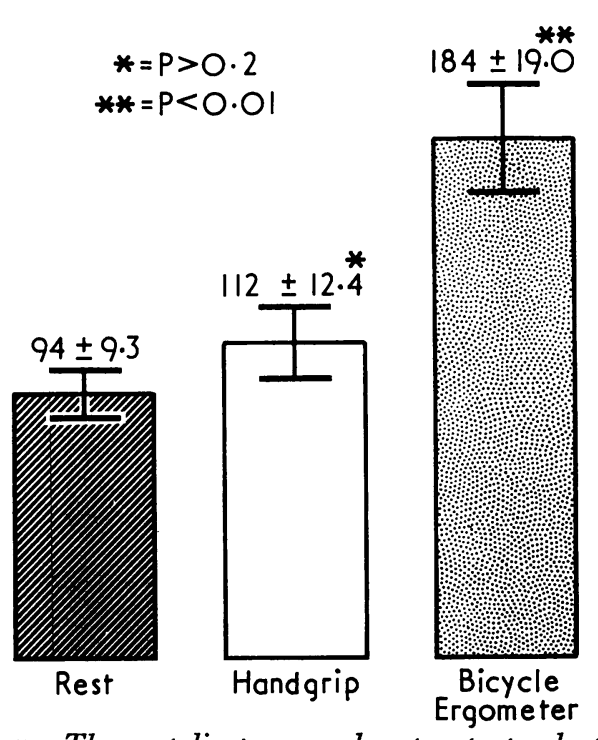

FIG. I The systolic pressure-heart rate product at rest, during isometric handgrip and bicycle ergometer exercise. The increase in product with handgrip does not achieve statistical significance when compared to rest values, while the product achieved during bicycle ergometry is significantly higher than that during handgrip $(P<0 \cdot 0 I)$.

\section{Correlation of degree of ST segment depres- sion and collaterals}

Table 4 illustrates the relation between the degree of ST segment depression and the presence or absence of coronary collaterals. Of 14 patients with $O$ and I mm ST segment depression, only 3 had coronary collateral vessels. In contrast, of 19 patients with 2 or more than $2 \mathrm{~mm}$ ST segment depression, I4 had coronary collaterals (Table 4). This difference is statistically significant $(\mathbf{P}<0.005)$.

\section{Correlation of degree of ST segment depres- sion and asynergy}

The relation between the presence or absence of asynergy and degree of ST segment depression is seen in Table 5. In 14 patients with 0 or I mm ST segment depression, 4 also had asynergy (3 hypokinesis; I akinesis). In contrast, of 19 patients with 2 or greater than $2 \mathrm{~mm} \mathrm{ST} \mathrm{segment} \mathrm{depression,} 15$ had asynergy on left ventriculography (8 hypokinesis; 3 akinesis; I dyskinesis; 3 combined hypokinesis and akinesis $)(\mathbf{P}<0.005)$.

\section{Discussion}

The results of this study indicate that bicycle ergometry exercise to 70 per cent of maximal predicted 


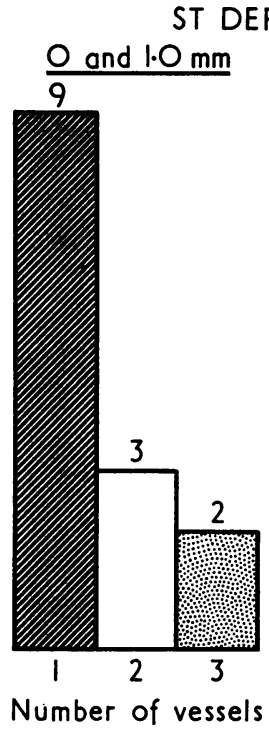

FIG. 2 Correlation of degree of ST segment depression and extent of coronary artery disease. Of 14 patients with o and $\mathrm{I} \cdot 0 \mathrm{~mm} S T$ segment depression, 9 had one-vessel disease, 3 had two-vessel disease, and 2 had three-vessel disease. Conversely, of patients with $2 \cdot 0$ or greater than $2.0 \mathrm{~mm} S T$ segment depression, only $I$ had one-vessel disease while 9 had truc-vessel and an additional 9 had three-vessel disease.

TABLE 4 Correlation of degree of $S T$ depression and collaterals

\begin{tabular}{lllll}
\hline \multirow{2}{*}{ Collaterals } & \multicolumn{4}{c}{$S T$ segment depression $(m m)$} \\
& 0 & $I$ & 2 & $>2$ \\
\hline Present & 2 & I & 7 & 7 \\
Absent & 5 & 6 & 2 & 3 \\
\hline
\end{tabular}

heart rate is of considerable value in the diagnosis of both the presence and extent of coronary artery disease. Thus, of 33 patients with arteriographic evidence of significant coronary obstructive disease, 26 had an abnormal exercise electrocardiogram. In contrast, of 30 patients with normal coronary arteries by arteriography, 5 had abnormal exercise electrocardiograms. Of these 5 patients, 2 were women who were diagnosed as having the syndrome of true angina pectoris with normal coronary arteriograms, and 2 additional patients had voltage criteria for left ventricular hypertrophy. These results are in general agreement with recent reports correlating the findings at coronary arteriography
TABLE 5 Correlation of degree of $S T$ depression and asynergy

\begin{tabular}{lllll}
\hline \multirow{2}{*}{ Asynergy } & \multicolumn{4}{c}{$S T$ segment depression $(m m)$} \\
& 0 & $I$ & 2 & $>2$ \\
\hline Present & I & 3 & 7 & 8 \\
Absent & 6 & 4 & 2 & 2 \\
\hline
\end{tabular}

with exercise testing based on heart rate response (Roitman et al., 1970).

In addition, a relation was found between the degree of ST segment depression and extensiveness of coronary artery disease. Thus, as the amount of ST depression increased, the number of vessels significantly obstructed also increased as well (Table 3). These data are in agreement with the findings of Most et al. (1969) correlating the extent of coronary disease with ST segment abnormalities produced by the Masters test (Most et al., 1969), though other investigators did not find a significant relation between degree of exercise electrocardiographic abnormalities and the extent of arteriographic abnormalities (Roitman et al., 1970). Recent preliminary reports, however, have indicated a correlation between the degree of ST segment depression and the extent of coronary artery disease (Moran et al., 1972; McHenry, Lisa, and Knoebel, 1970).

Perhaps somewhat paradoxically, coronary collaterals were found with greater frequency in patients with more severe ST segment depression with exercise (Table 4). These findings are in agreement with previous studies employing the Masters test (Most et al., 1969; Helfant, Vokonas, and Gorlin, I97Ib). These data are consistent with the experimental observations that collateral blood flow is relatively fixed and cannot readily increase with most physiological stresses (Kattus and Gregg, 1959).

A correlation was also found in the present study between the degree of ST segment depression and the presence of abnormalities of left ventricular contraction (asynergy). This left ventricular contraction finding may imply a relation between local ischaemia and a concurrent abnormality of contraction. Previous studies have indicated a relation between regional metabolic abnormalities indicating myocardial ischaemia and abnormalities of ventricular contraction. Conversely, this finding can be explained by the increased incidence of asynergy with more extensive coronary obstructive disease (Helfant, Kemp, and Gorlin, 1970). It is also of interest in this regard that a recent preliminary report 
has indicated a correlation between the degree of ST segment depression on exercise and a rise in pulmonary capillary wedge pressure with exercise (Herman, Elliott, and Gorlin, 1967).

In contrast to bicycle ergometry, the isometric stress of sustained handgrip was not found to be of value in the diagnosis of coronary heart disease. Thus, of 31 patients with abnormal coronary arteriograms, only 3 had abnormal reponses on the electrocardiogram to sustained handgrip (Table 2). An explanation for this finding may be indicated by Fig. I which illustrates that the rate-pressure product with bicycle ergometry is significantly higher than with handgrip. Robinson (1967) has shown that the rate-pressure product is a good approximation of myocardial oxygen consumption. It is probable that the increase in myocardial oxygen consumption produced by sustained handgrip exercise is inadequate to exceed the 'ischaemic threshold' of the majority of patients with coronary heart disease.

\section{References}

Bruce, R. A., and Hornsten, T. R. (1969). Exercise stress testing inevaluation of patients with ischaemic heart disease. Progress in Cardiovascular Diseases, II, 371.

Demany, M. A., Tambe, A., and Zimmerman, H. A. (1967). Correlation between coronary ateriography and the postexercise electrocardiogram. American fournal of Cardiology, 19, 526.

Elliott, W. C., and Gorlin, R. (1966). The coronary circulation, myocardial ischemia, and angina pectoris (II). Modern Concepts of Cardiovascular Disease, 35, 117.

Helfant, R. H., deVilla, M. A., and Meister, S. G. (1971a). Effect of sustained isometric handgrip exercise on left ventricular performance. Circulation, 44, 982.

Helfant, R. H., Kemp, H. G., and Gorlin, R. (1970). Coronary atherosclerosis, coronary collaterals, and their relation to cardiac function. Annals of Internal Medicine, 73, 189.
Helfant, R. H., Vokonas, P. S., and Gorlin, R. (I97Ib). Functional importance of the human coronary collateral circulation. New England fournal of Medicine, 284, 1277.

Herman, M. V., Elliott, W. C., and Gorlin, R. (1967). An electrocardiographic, anatomic and metabolic study of zonal myocardial ischemia in coronary heart disease. Circulation, 35, 834 .

Kattus, A. A., and Gregg, D. E. (1959). Some determinants of coronary collateral blood flow in the open-chest dog. Circulation Research, 7, 628.

McHenry, P. L., Lisa, C. P., and Knoebel, S. B. (1970). Correlation of treadmill exercise electrocardiogram with arteriographic location of coronary disease (abstract). American fournal of Cardiology, 26, 649.

Mason, R. E., Likar, I., Biern, R. O., and Ross, R. S. (1967) Multiple-lead exercise electrocardiography. Circulation, 36, 517.

Master, A. M., and Jaffe, H. L. (194I). The electrocardiographic changes after exercise in angina pectoris. Fournal of the Mount Sinai Hospital, 7, 629.

Moran, J. F., Amirparviz, F., Scanlon, P. J., Talano, J. V., Nemikas, R., Gunnar, R., and Tobin, J. R. (1972). Correlation of ST segment response in other parameters in the exercise ECG to coronary artery disease. Circulation, Suppl. 2, 46, 193.

Most, A. S., Kemp, H. G., and Gorlin, R. (1969). Postexercise electrocardiography in patients with arteriographically documented coronary artery disease. Annals of Internal Medicine, 7r, ro43.

Robinson, B. F. (1967). Relation of heart rate and systolic blood pressure to the onset of pain in angina pectoris. Circulation, 35, 1073.

Roitman, D., Jones, W. B., and Sheffield, L. T. (1970). Comparison of submaximal exercise ECG test with coronary cineangiocardiogram. Annals of Internal Medicine, 72, 64I.

Sheffield, L. T., Holt, J. H., and Reeves, T. J. (1965). Exercise graded by heart rate in electrocardiographic testing for angina pectoris. Circulation, 32, 622.

Requests for reprints to Dr. Richard H. Helfant, Division of Cardiology, Presbyterian-University of Pennsylvania Medical Center, 5I North 39th Street, Philadelphia, Pennsylvania 19104, U.S.A. 